\title{
Survival of neonates and predictors of their mortality in Tigray region, Northern Ethiopia: prospective cohort study
}

\author{
Hayelom Gebrekirstos Mengesha ${ }^{1,2^{*}}$, Alem Desta Wuneh ${ }^{2}$, Wondwossen Terefe Lerebo ${ }^{2}$ and Tesfay Hailu Tekle ${ }^{2}$
}

\begin{abstract}
Background: Neonatal mortality accounts for an estimated 2.8 million deaths worldwide, which constitutes $44 \%$ of under-5-mortality and $60 \%$ of infant mortality. Neonatal mortality predictors vary by country with the availability and quality of health care. Therefore, aim of this study was to estimate survival time and identify predictors of neonatal mortality in Tigray region, northern Ethiopia.

Method: A prospective cohort study design was carried out among a cohort of neonates delivered in seven hospitals of Tigray from April to July, 2014 and followed up for a total of 28 days. Data were collected by interviewing mothers using structured questionnaires and assessments of the neonate and mothers by midwives. Kaplan-Meier, Log rank test and Cox-proportional hazard regressions were used. STATA V-11 program was used for data entry, cleaning and analysis.

Results: From 1152 neonates, 68 died (neonatal mortality rate 62.5/1000 live births), 73.52 \% of the neonates died within 7 days, 60 were lost to follow-up and the percentage of survival at 28 days was $93.96 \%$ (95 \% Cl: 92.4, 95. $2 \%)$. Predictors of neonatal mortality were: normal birth weight (AHR: $0.45,95 \% \mathrm{Cl}: 0.24,0.84$ ), not initiating exclusive breastfeeding (AHR: 7.5, 95 \% Cl: 3.77, 15.05), neonatal complications (AHR: 0.14, 95 \% Cl 0.07, 0.29), maternal complications (AHR: 0.37, 95 \% Cl: 0.22, 0.63) and proximity (AHR: 2.5, 95 \% Cl: 1.29, 4.91).

Conclusion: Neonatal mortality is unacceptably very high. Managing complications and low birth weight, initiating exclusive breast feeding, improving quality of services and ensuring a continuum of care are recommended to increase survival of neonates.
\end{abstract}

Keywords: Ethiopia, Neonatal mortality, Survival analysis, Tigray region

\section{Background}

Neonatal mortality (NM) accounts for an estimated 2.8 million deaths worldwide [1], which constitute $44 \%$ of child mortality and over $60 \%$ of infant mortality $[1,2]$. Most of these (99\%) arise in low-income and middleincome countries [3]. Hence, special endeavors should be undertaken to reduce the proportion of $\mathrm{NM}$ in under-five mortality (U5M). Sub-Saharan Africa carries the highest NM in the world and made the lowest progress in reducing NM $[1,2]$. In Ethiopia, the proportion of $\mathrm{NM}$ in U5M became $42 \%$ in 2011 [4]. A recent report in 2014 indicates that Ethiopia has achieved

\footnotetext{
* Correspondence: hayetgeb@gmail.com

${ }^{1}$ Adigrat University, College of Medicine and Health science, Adigrat, Ethiopia

${ }^{2}$ Mekelle University, College of Health Science, Mekelle, Ethiopia
}

Millennium Development Goal-4 in 2012 [1] and an increasing number of the remaining child mortalities are attributed to NM intrinsically linked to maternal health and nutrition [5]. Ethiopia's achievements have been attributed to the country community-based health promotion and disease prevention strategies [6]. In addition, for years, Ethiopia has been implementing integrated services of Emergency Obstetric and Newborn Care to improve neonatal and maternal care $[7,8]$ and to reduce neonatal deaths. Ethiopia neonatal mortality rate (NMR) in 2011 was $37 / 1000[4,9]$ and this rate varies by region from 21-62/1000 live births. The Tigray region (in which the study was conducted) NMR was 44/1000 [4].

High maternal and neonatal mortality and still birth often occur because of inadequate care during pregnancy 
and childbirth. Hence, these deaths are considered as sensitive indicators of the quality of the healthcare system in the area [10]. One-third to half of NM occurred within 24-h and $75 \%$ occurred in the first week of life $[1,3,11,12]$ because of complications during pregnancy and childbirth [1-3]. Many studies have revealed NM is influenced by multiple factors [3, 13-16]. Previous reports in Ethiopia showed the causes of NM as sepsis, asphyxia, birth injury, tetanus, preterm birth, congenital malformations and unknown causes [17]. However, these reports are either hospital based secondary records [18] or retrospective household surveys [4].

Furthermore, causes of NM vary by country and region with the availability and quality of health care, therefore, understanding NM in relation to these factors is crucial $[3,19,20]$. This is because there are highly feasible and cost-effective interventions that could avert NM up to $72 \%$, and this can only be achieved if countries adopt locally relevant and focused interventions that are guided by evidence $[1,3]$. Considering the paucity of reliable and documented evidence on NM in the study region, Tigray, we aimed at clearly identifying predictors and estimating survival time of neonates delivered in hospitals of Tigray region, which have access to skilled birth and obstetric care. This included all proximate and distal determinants of NM and following up prospectively from birth up to 28 days.

\section{Methods}

\section{Study design, setting and population}

A prospective cohort study was conducted among a cohort of neonates delivered between April 2014 and July 2014 in randomly selected seven hospitals of Tigray region, which is one of the nine administrative Federal regions of Ethiopia. Tigray region has an estimated total population of 4,565,000, (2,314,000 women and 2,251,000 men). The Ethiopian health care has a decentralized four-tier system of primary, district, zonal and specialized hospitals. The primary care includes rural health posts, nested into health centers serving 25,000 populations. District hospitals form the tiers expected to serve 250,000 catchment populations. Zonal and specialized hospital serves 500,000 and 5,000,000 populations respectively. In Tigray region, one of the 11 administrative states in Ethiopia, has a total of 15 public hospitals; 6 zonal, 1 specialized hospitals, and the remaining 8 in the district and primary health care category. All hospitals provide maternal and newborn services including delivery services free of charge. Seven hospitals were randomly selected from the 15 hospitals of the region by lottery method [21]. All mothers who gave a live birth in the study hospitals came from the entire region were included in this study and followed up for a total of 28 days.

\section{Inclusion and exclusion criteria}

Mothers with their Neonates, who gave live birth in the study hospitals or admitted within six hours, from April -July, 2014 were included in the study. Mothers who were unable to speak and mothers with psychiatric illnesses were excluded from the study.

\section{Sample size}

The sample size was 1162 neonates, which were determined by using STATA statistical package, Version 11.0. Based on the assumptions of 2.19 hazard-ratio [22] associated preceding birth of the mother, there was a variability of 0.5 , probability of death 0.044 [4], $5 \%$ marginal error and $95 \%$ confidence interval of certainty to have a power of $80 \%$. It was assumed that no subjects were anticipated to withdraw from the follow-up.

\section{Data collection, participants, recruitment and follow-up}

Data were collected prospectively using pre-tested structured questionnaires and using a checklist for data that were collected from assessments of the neonate and mother. The questionnaire was derived from related literatures and WHO standard verbal autopsy questionnaires [23]. The questionnaire was initially developed in English and translated into local language, Tigrigna. Two midwives, with a qualification of university degree and can speak the local language from each hospital were recruited for data collection. The data collectors had been collecting information by interviewing all mothers who delivered a live birth at the selected hospitals within the first 6-h after delivery. Besides, the clinical information was extracted by assessment of the neonate and mother. Mothers and live births were followed for 28 days, using three alternatives. The data collector visited the neonate daily, while he/she was in the hospital. After the mother was discharged; the data collector met the mother every 7 -days either using a phone call or by creating liaison with a health extension worker and inquired about the neonatal condition and survival. Mothers who were not at home during the scheduled visit were revisited. When death occurred, the date and cause of death was recorded and probable cause of death was assigned after agreement between midwives and physicians based on national guidelines [24] and the International classification of disease [25]. The data that were collected prospectively consisted of Time to death of neonates (Dependent variable), and the socio-demographic, economical, neonatal, and maternal and health service-related characteristics (independent variables).

\section{Definition and measurement of variables}

The inclusion of variables was partly guided by the Mosley and Chen conceptual framework [26] previously used in similar studies with some modifications. The 
factors influencing NM were broadly categorized as follows:

\section{Distal (socioeconomic and demographic factors)}

The variables assessed in this category were: monthly reported income categorized into, low $(<500$ ETB), medium (500-1500 ETB) and rich (>2000ETB), and residence classified into 'rrban'/'rural'. Age at first marriage was measured in continuous scale yet for the sake of analysis later it was categorized into below age of 18 (teenagers), '18 years and above'. Similarly, educational status was first categorized in to 'unable to read and write",able to read and write but no formal education', '1-4 grade', '5-8 grade', '9-12 grade', 'college and above' but later during analysis considering the few number of observations in the 'able to read \& write' category, we merged it into (unable to read \& write with able to read \& write), and finally categorized into : '(unable to write \& read or no formal education)', 'primary education (1-8 grade)', 'secondary (9-12 grade)' and 'tertiary (college and above grades)'.

Likewise, marital status was first categorized into married (living together), single, widowed, divorced and separated but later during analysis due to few observations, we merged the categories other than the 'married' category in to 'others'. Occupation was classified based on the mothers report into 'house wife/farmer', 'own business' 'government employee' and 'student'.

\section{Proximal factors (maternal, neonatal and health service related)}

This category includes: Gestational age, which was measured by using last menstrual period and/or ultrasound. Gestational age was categorized into preterm ( $<259$ days), term (259-293 days) and post term birth (> = 294 days) but during analysis due to the few observations of post term births coded with term birth. Birth weight was defined according to the WHO classification as low birth weight ( $<2500$ gm); normal birth weight ( $>=2500$ and $<4000$ gm); and macrosomia ( $>=4000 \mathrm{gm}$ ) [27] but later during analysis, it was coded into low birth weight and normal birth weight ( $>=2500 \mathrm{gm}$ ) and it was measured using a standard beam balance within six hours of delivery.

Body mass index (BMI), measured by a standard height, weight measuring instrument found in the study hospitals and was categorized into underweight (BMI less than 18.5), normal (BMI 18.5-24.9), Overweight (BMI $\geq 25.0)$. Weight for gestational age was categorized according to WHO definitions into: 'Large for gestational age' was defined as a birth weight greater than the $90^{\text {th }}$ percentile for age, 'Small for gestational age' birth weights below the 10th percentile. 'Appropriate for gestational age' defined as birth weight between the 9010th percentile [28]. The cut off points of weight for gestational age was derived from Alexander et al. described elsewhere [29] and adapted to our study with some modifications.

In our study, fertility (no of children) defined as the actual production of live offspring excluding stillbirths, fetal deaths and abortions. It was classified into primiparae (only the current birth), 2-4 and multiparty $(>=5)$. But parity was defined as the number of full term children previously borne by a woman, excluding miscarriages or abortions in early pregnancy, but in contrast to fertility it includes stillbirths. It was categorized into 'none' 'one' 'two' and '> = three'.

We defined gravidity as the number of pregnancies (completed or incomplete) experienced by a woman in contrast to fertility and gravidity it includes all pregnancies. We categorized it into 'no pregnancy', 'one pregnancy', 'two pregnancy' and '> = three pregnancy'.

Antenatal follow up was assessed by categorizing in to 'Yes', if the mother ever had at least one antenatal follow up, 'No' if the mother never had antenatal follow up.

Diagnosed medical disease was assessed using, 'Yes' if the mother had a medically known/diagnosed disease such as HIV/AIDS, Hypertension, Diabetes mellitus, epilepsy and 'others'. 'No', if the mother did not have medically diagnosed disease.

History abortion defined as mother history of abortion either induced, spontaneous or self initiated abortion before the current birth. It was categorized into 'Yes'/'No'.

Induced abortion was defined as an abortion induced medically by a health professional, but self induced abortion was defined as abortion initiated by the women without medical and legal indication. Spontaneous abortion was defined as an abortion, which is neither medically induced nor self initiated, but the fetus spontaneously aborted itself. Similarly, history of still birth was categorized into 'Yes' and 'No'.

Place of birth (inborn or out born) was defined 'Inborn' if the neonate was delivered inside the study hospitals, 'out born' if the neonate was delivered in either health facility or home outside the study hospital. We categorized into 'Yes' if inborn or 'No' if out born.

Place of death was defined as the place where the neonate died after included in the study, which was categorized into 'hospital' if the neonate died inside the hospital where he/she delivered, 'Home' if he/she died after discharged from the given hospital, 'other health facility' if the neonate died in other health facility other than the given hospital.

Birth type was initially categorized into 'single', 'twin', 'triple and above'. Yet for the purpose of analysis twin and triple birth were merged into 'Multiple births'. Mothers who gave twin and triple birth were counted separately for each birth for the sake of analysis. 
Distance was recorded in continuous scale, but later categorized in to $<5 \mathrm{~km}$ far from the nearest health facility, $5-10 \mathrm{~km}$ and $>=10 \mathrm{~km}$ far from the nearest health facility.

Mode of delivery is classified into 'spontaneous vaginal delivery', 'operative (instrumental) vaginal delivery' and 'cesarean section'. Instrumental delivery was defined as the application of either forceps or a vacuum device to assist the mother in effecting vaginal delivery of a fetus.

\section{Immediate (Intervention) factors}

The variables considered in this category were: Hypothermia in which it was classified according to WHO recommendations into 'Yes' if body temperature below the normal range $\left(36.5{ }^{\circ} \mathrm{C}-37.5{ }^{\circ} \mathrm{C}\right)$, 'No' if it is within the normal range and above [30].

Temperature control for the hypothermic neonates categorized into: 'Yes' if the hypothermic neonate temperature returns to normal after appropriate interventions was undertaken and 'No' if the hypothermic neonate temperature is not returned to normal range after the intervention. We did not consider this variable in the Cox-regression model due to large missing values.

Exclusive breast feeding (EBF) (Yes/No): was defined as feeding with only breast milk and nothing else, with the exception of vitamin supplements and prescribed medicines.

Maternal complication categorized into 'yes' or 'No', which is considered present if the mother had an obstetric hemorrhage, puerperal sepsis and pyrexia, prolonged labor, eclampsia and preeclampsia, mal-presentation and mal-position, premature rupture of membrane (PROM), cord prolapse, obstructed labor, cephalopelvic disproportion (CPD), emergency cesarean section, and retained placenta.

Neonatal complication is considered presented if the neonate had asphyxia, prematurity, infection, hypothermia, jaundice and other rare complications during birth.

\section{Outcome variable}

Early neonatal mortality rate (ENM) was defined as the probability of dying before 7 completed days of life. Late neonatal mortality rate (LNM) as the probability of dying between 7 completed days and before 28 completed days; and overall NM was defined as death of a newborn within 28 days of his/her birth. NMR was defined as the number of deaths of neonates per 1000 live births. NM was categorized into 'Yes' if the neonate died 'No' if the neonate censored.

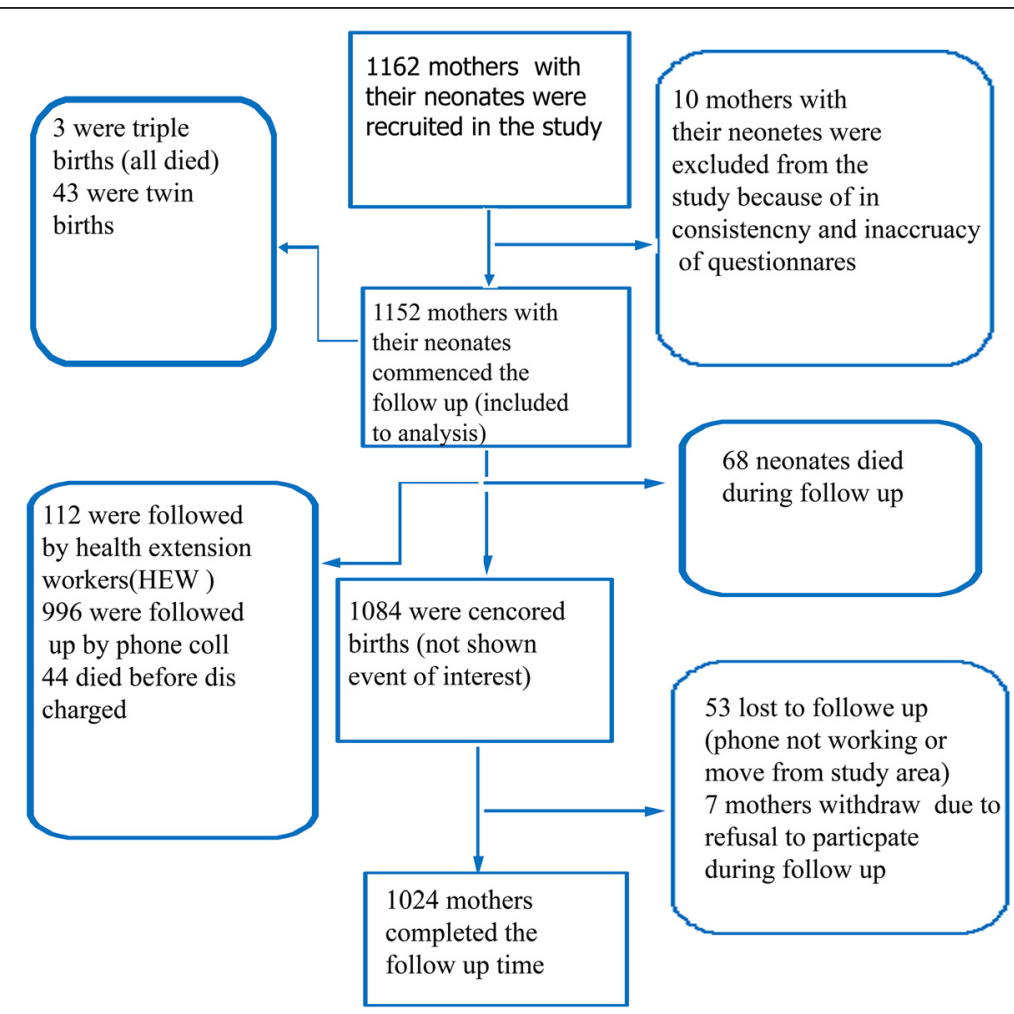

Fig. 1 Flow diagram of the overall recruitment and follow up process of mothers and neonates in Tigray region, northern Ethiopia, April-July, 2014. In this figure Health extension worker (HEW) means a female completed $10^{\text {th }}$ grade education and received one year training in providing prevention services including breastfeeding, safe and clean delivery, basic antenatal and post-neonatal care. The topics include immunization, family planning, and management of childhood illnesses. The HEWs serves communities in which they reside 
Censored births were the neonates who were alive at the end of follow up, withdrawal and lost-to-follow-up. Time-to-death was defined as death of a neonate at specific time (day) within the 28 days follow-up time.

The outcome of the follow up was categorized into 'death' if he/she died during follow up, 'lost to follow up' if the mother phone was not working, moves to another area from the original place of residence and not met by health extension worker. 'Withdrawal' if the mother refuses the follow up due to inconvenience and 'alive' if the neonate survival is assured by the data collector at the last follow- up time.

\section{Data management and analysis}

Death of neonate was the event of interest and the coding were " 1 " for death and " 0 " for censored. Time-todeath was calculated by subtracting the date of death from birth.

Data was entered, cleaned, recoded and analyzed using STATA version-11.1. For description, frequencies, percentages, and rates, Kaplan Meier curves were used to estimate survival time. Log-rank test was used to look statistical differences among/between the categories of variables. To identify potential predictors of NM, Coxproportional hazard regression model was fitted by successive stepwise backward elimination. Statistical significance was declared at $\mathrm{p}$-value $<0.05$. Confounding and effect modification was checked by looking at regression coefficient change if greater than or equal to $15 \%$ and multi-collinearity was checked using variance inflation factor and value of $<10$ was used as a cutoff point, indicating no colinearity.

Proportional hazard assumption was tested by using covariate specific Proportional hazard assumption test. Residuals were checked using goodness-of-fit test by Cox Snell residuals.

\section{Ethical clearance}

Ethical clearance was obtained from Mekelle University, College of Health Sciences Ethical review board. Permission letters were also sought from Tigray Regional Health Bureau. Written Informed consent from the mother was obtained after clear explanation of the purpose of the study. Confidentiality and anonymity was maintained.

\section{Results}

\section{Response rate and sociodemographic characteristics}

Response was obtained from all participants $(n=1162)$, however, ten $(0.96 \%)$ observations were excluded from the analysis due to incompleteness (Fig. 1). Of these $(n=1152)$ mothers, 1071 (92.97\%) were married, 368 (31.94 \%) of the live births were from teenage mothers (below the age of 18 years), nearly one third $361(31.34 \%)$ of the mothers had completed secondary school and $373(36.73 \%)$ of the mothers had a reported monthly income $>1500$ ETB (Table 1 ).

\section{Maternal and pregnancy characteristics}

Among the total mothers recruited into the study, 172 (14.9\%) of the mothers had previous history of abortion and 91 (7.9\%) of the mothers had a history of stillbirth. The mean and standard deviation of the current age of mothers was $26.65(\mathrm{sd}= \pm 5.4)$.

Regarding medically diagnosed diseases, 100 (8.7\%) had medically known disease. Of these, hypertension had highest prevalence 26 (26\%). But some mothers had two medically diagnosed diseases at the same time, for instance, both hypertension and HIV, for this reason the

Table 1 Socioeconomic and demographic characteristics of mothers who gave live births in the randomly selected hospitals of Tigray region, northern Ethiopia, April-July, $2014(n=1152)$

\begin{tabular}{|c|c|c|}
\hline Characteristics & No. & Percent \\
\hline \multicolumn{3}{|l|}{ Hospital } \\
\hline Ayder Referral Hospital & 139 & 12.1 \\
\hline Adwa Hospital & 198 & 17.2 \\
\hline Lemlem Karl Hospital & 147 & 12.8 \\
\hline Suhl Hospital & 143 & 12.4 \\
\hline Kahsay Abera Hospital & 102 & 8.8 \\
\hline Kidist maram Hospital & 213 & 18.5 \\
\hline Adigrat Hospital & 210 & 18.2 \\
\hline \multicolumn{3}{|l|}{ Age at marriage } \\
\hline$<18$ year & 68 & 31.9 \\
\hline$\geq 18$ year & 784 & 68.1 \\
\hline \multicolumn{3}{|l|}{ Religion } \\
\hline Orthodox & 1084 & 94.1 \\
\hline Other & 68 & 5.9 \\
\hline \multicolumn{3}{|l|}{ Residence } \\
\hline Rural & 397 & 34.5 \\
\hline Urban & 755 & 65.5 \\
\hline \multicolumn{3}{|l|}{ Educational status } \\
\hline Unable to read & 275 & 23.9 \\
\hline Primary & 338 & 29.3 \\
\hline Secondary & 361 & 31.3 \\
\hline Tertiary & 178 & 15.5 \\
\hline \multicolumn{3}{|l|}{ Monthly income } \\
\hline Poor & 327 & 32.19 \\
\hline Medium & 316 & 31.1 \\
\hline Rich & 373 & 36.71 \\
\hline \multicolumn{3}{|l|}{ Marital status } \\
\hline Married & 1071 & 93.0 \\
\hline Other & 81 & 7.0 \\
\hline
\end{tabular}

Rich: $\geq 1500$ Ethiopian birr (ETB), Medium: 600-1500 ETB, Poor: <600 ETB 
Table 2 Characteristics of mothers who gave live births in the randomly selected hospitals of Tigray region, northern Ethiopia, April -July, $2014(n=1152)$

\begin{tabular}{|c|c|c|c|c|c|}
\hline Characteristics & No. & Percent & Characteristics & No. & Percent \\
\hline Age at first birth & & & Parity & & \\
\hline$<20$ year & 382 & 33.3 & & & \\
\hline 20-24 year & 551 & 47.9 & None & 561 & 48.7 \\
\hline$>24$ year & 216 & 18.8 & One & 147 & 12.8 \\
\hline Current age of mother & & & Two & 175 & 15.2 \\
\hline$<20$ year & 95 & 8.2 & $\geq$ Three & 269 & 23.3 \\
\hline 20-24 year & 328 & 28.5 & History of abortion & & \\
\hline 25-34 year & 590 & 57.2 & Yes & 172 & 14.9 \\
\hline$\geq 35$ year & 139 & 12.1 & No & 980 & 85.1 \\
\hline Number of children & & & Reason of abortion $(n=172)$ & & \\
\hline Primiparae & 610 & 53.0 & Spontaneous & 138 & 80.2 \\
\hline 2-4 children & 424 & 36.8 & Self initiated & 13 & 7.6 \\
\hline Multiple $(\geq 5)$ & 118 & 10.2 & Induced & 21 & 12.2 \\
\hline Birth type & & & Number of abortion & & \\
\hline Single & 1057 & 91.7 & One & 147 & 85.5 \\
\hline Multiple $^{\mathrm{b}}$ & 95 & 8.3 & Two & 19 & 11.0 \\
\hline Gravidity & & & $\geq$ Three & 3.49 & 3.5 \\
\hline No pregnancy & 475 & 41.2 & History of still birth & & \\
\hline One pregnancy & 191 & 16.6 & Yes & 91 & 7.9 \\
\hline Two pregnancy & 170 & 14.8 & No & 1061 & 92.1 \\
\hline$\geq$ Three pregnancy & 316 & 27.4 & Number of still birth & & \\
\hline Birth interval & & & One & 69 & 75.8 \\
\hline Not applicable & 537 & 46.6 & Two & 19 & 20.9 \\
\hline$<$ Two years & 127 & 11.0 & $>$ Two & 3 & 3.3 \\
\hline$>$ Two years & 488 & 42.4 & Diagnosed disease & & \\
\hline Ever use of $\mathrm{FR}^{\mathrm{a}}$ & & & Yes & 100 & 8.7 \\
\hline Yes & 650 & 56.42 & No & 1052 & 91.3 \\
\hline No & 502 & 43.58 & Type of disease $(n=100)$ & & \\
\hline Method used $(n=650)$ & & & Hypertension & 26 & 26 \\
\hline Oral & 76 & 11.7 & Hemorrhage & 6 & 6 \\
\hline Implant & 97 & 14.9 & Other & 68 & 68 \\
\hline Injection & 461 & 70.8 & & & \\
\hline Other & 17 & 2.6 & & & \\
\hline Rhesus immunization status & & & Disease others $(n=73)$ & & \\
\hline Positive & 989 & 85.8 & HIV & 31 & 42.5 \\
\hline Negative & 163 & 14.2 & TB & 7 & 9.6 \\
\hline \multirow[t]{2}{*}{ Maternal complications } & & & Malaria & 6 & 8.2 \\
\hline & & & Other & 29 & 39.7 \\
\hline Yes & 221 & 19.2 & Tetanus injection & & \\
\hline No & 930 & 80.8 & Yes & 998 & 86.6 \\
\hline Type of complication ${ }^{c}(n=220)$ & & & No & 154 & 13.4 \\
\hline APH & 22 & 10 & Number of Tetanus injection & & \\
\hline
\end{tabular}


Table 2 Characteristics of mothers who gave live births in the randomly selected hospitals of Tigray region, northern Ethiopia, April -July, 2014 ( $n=1152)$ (Continued)

\begin{tabular}{|c|c|c|c|c|c|}
\hline $\mathrm{PPH}$ & 30 & 13.6 & One injection & 93 & 9.3 \\
\hline $\mathrm{PIH}$ & 24 & 10.9 & $\geq$ Two injection & 908 & 90.7 \\
\hline Prolonged/Obstruct & 36 & 16.4 & Mortality of older sibling & & \\
\hline CPD & 20 & 9.1 & Yes & 82 & 7.1 \\
\hline PROM & 12 & 5.4 & No & 1070 & 92.9 \\
\hline Mal presentations & 18 & 8.2 & Assistance during delivery & & \\
\hline Other & 58 & 26.4 & Midwife & 830 & 72.1 \\
\hline Antenatal utilization & & & Gyn/obstetrician & 148 & 12.8 \\
\hline Yes & 1131 & 98.2 & Emergency Surgery & 138 & 12.0 \\
\hline No & 21 & 1.8 & Other & 36 & 3.1 \\
\hline Who attend & & & Mode of delivery & & \\
\hline Skilled worker & 1096 & 96.9 & Vaginal & 846 & 73.4 \\
\hline Other & 35 & 3.1 & Cesarean section & 241 & 20.9 \\
\hline No of antenatal utilization & & & Instrumental & 65 & 5.7 \\
\hline$\geq 4$ Visits & 823 & 74.1 & & & \\
\hline$<4$ Visits & 287 & 25.9 & & & \\
\hline
\end{tabular}

${ }^{\mathrm{a}}$ Family planning

${ }^{\mathrm{b}}$ All multiple births were counted separately

${ }^{c} A P H$, Ante Partum Hemorrhage; PPH. Post partum Hemorrhage; PIH, Pregnancy induced hypertension; Gyn, Gynecologist; Obstruct, Obstructed labor; CPD, Cephalo Pelvic Disproportion; PROM, Premature Rupture of Membrane; HIV, Human Immuno Deficiency virus; TB, Tuberculosis

'disease others' category instead of comprising 68 mothers, it became 73 mothers. It was due to 5 mothers that had double burden of disease simultaneously (Table 2).

\section{Neonatal and health service characteristics}

Regarding the neonatal characteristics, the female to male ratio was 1:1.1. The mean and standard deviation of birth weight and gestational age were 3058 $(\mathrm{sd}= \pm 588)$ and $273(\mathrm{sd}= \pm 14.3)$ respectively. Of the total, 1012 (87.8 \%) neonates received EBF and 180 (15.6\%) were large for gestational age neonates. In our study, only few 67 (5.8\%) neonates were outside the study hospitals (out bearing). Among all respondents, 836 (76.3\%) of the mothers were living in $<5 \mathrm{~km}$ distance to the nearest health facility (Table 3 ).

\section{Survival analysis and outcome of the follow up}

Neonates were followed up for 27357.508 neonate-days. In the study, $22.05 \%$ of neonatal deaths occurred in the first 24 hours, $47.0 \%$ in the next 3 days and $73.5 \%$ of the neonatal deaths occurred within 7 days. The remaining $26.5 \%$ died in the next 14 days. The cumulative survival rate of neonates at the end of the follow up were $93.96 \%$ (95 \% CI: 92.38, 95.21) (Table 4 and Fig. 2). Overall, in this study 68 (6.2\%) neonates died which makes the NMR 62.5 per 1000 live births. At the end of follow up, $1024(88.9 \%)$ were alive, 53 (4.6\%) lost to follow up and $7(0.6 \%)$ were withdrawal (Fig. 1). The leading cause of death were $23(34 \%)$ premature and low birth weight and 21 (31\%) asphyxia, 8 (12\%) infections, 5 (7\%) congenital abnormality and $11(16 \%)$ died due to other causes. One third (33\%) of the neonates died at home after discharged from the respective hospitals, while $44(64.7 \%)$ died in the study hospitals and 2 (2.9\%) died in other health facility.

\section{Bivariate and multivariate analysis}

The log rank test results showed that, survival pattern or time to neonatal mortality has significantly varied over the categories of: birth weight $\left(X^{2}\right.$ for Log rank test $=135.9, p=0.00)$, place of residence $\left(X^{2}=13.1, P=\right.$ $0.0003)$, number of children $\left(X^{2}=12.5, P=0.0019\right)$, history of stillbirth $\left(X^{2}=17.1, P=0.00\right)$, history of abortion $\left(x^{2}=\right.$ 9.7, $P=0.0019)$, birth type $\left(X^{2}=29.1, P=0.00\right)$, maternal complication $\left(X^{2}=42.3, P=0.00\right)$, EBF $\left(X^{2}=275.6, P=\right.$ $0.00)$, neonatal complication $\left(X^{2}=316.1, P=0.00\right)$, weight for GA $\left(X^{2}=19.5, P=0.00\right)$, hypothermic birth, 1 and 5 min Apgar score, length of neonate, birth defect, distance to nearest health facility, delivery assistance and place of delivery (Table 5).

Multivariable analysis revealed that a neonate born with normal birth weight (2500-3500 gm) had $55 \%$ lesser hazard of neonatal death compared to neonates born with a birth weight of less than 2500 gm (low birth 
Table 3 Neonatal and health service related characteristics of neonates delivered in randomly selected hospitals of Tigray region, Northern Ethiopia, April-July, 2014 ( $n=1152)$

\begin{tabular}{|c|c|c|c|c|c|}
\hline Characteristics & No & Percent & Characteristics & No & Percent \\
\hline \multicolumn{3}{|l|}{ Sex } & \multicolumn{3}{|l|}{ Apgar 5-min score } \\
\hline Male & 610 & 52.9 & Severe $(\leq 3)$ & 8 & 0.7 \\
\hline Female & 542 & 47.1 & Moderate (3-6) & 45 & 4 \\
\hline \multicolumn{3}{|c|}{ Exclusive breast feed } & Normal $(\geq 7)$ & 1081 & 95.3 \\
\hline Yes & 1012 & 87.8 & \multicolumn{3}{|l|}{ Birth defect } \\
\hline No & 140 & 12.2 & Yes & 14 & 1.2 \\
\hline \multicolumn{3}{|l|}{ Resuscitation } & No & 1138 & 98.8 \\
\hline Yes & 154 & 13.4 & \multicolumn{3}{|c|}{ Neonatal length $(n=1126)$} \\
\hline No & 998 & 86.6 & $<46 \mathrm{~cm}$ & 151 & 13.4 \\
\hline \multicolumn{3}{|l|}{ Apgar 1-min score } & $46-56 \mathrm{~cm}$ & 914 & 81.2 \\
\hline Severe $(\leq 3)$ & 19 & 1.7 & $>56 \mathrm{~cm}$ & 61 & 5.4 \\
\hline Moderate (3-6) & 166 & 14.6 & \multicolumn{3}{|l|}{ Birth weight } \\
\hline Normal $(\geq 7)$ & 950 & 83.7 & $<2500 \mathrm{gm}$ & 121 & 10.5 \\
\hline \multicolumn{3}{|c|}{ Neonatal complications } & $2500-3500$ & 853 & 74.3 \\
\hline Yes & 126 & 10.9 & $>3500 \mathrm{gm}$ & 175 & 15.2 \\
\hline No & 1026 & 89.1 & \multicolumn{3}{|l|}{ Gestational age } \\
\hline \multicolumn{3}{|c|}{ Temperature control $(n=61)$} & Preterm & 93 & 8.1 \\
\hline Yes & 59 & 97 & Term & 1054 & 91.9 \\
\hline No & 2 & 3 & \multicolumn{3}{|c|}{ Weight for Gestational Age } \\
\hline \multicolumn{3}{|l|}{ Hypothermic } & Appropriate & 846 & 73.5 \\
\hline Yes & 61 & 5.3 & SGA & 125 & 10.9 \\
\hline No & 1091 & 94.7 & LGA & 180 & 15.6 \\
\hline \multicolumn{3}{|c|}{ Neonate inborn or out born } & \multicolumn{3}{|l|}{ Distance } \\
\hline Yes & 1085 & 94.2 & $\leq 5 \mathrm{~km}$ & 836 & 76.3 \\
\hline \multirow[t]{2}{*}{ No } & 67 & 5.8 & $5-10 \mathrm{~km}$ & 175 & 16.0 \\
\hline & & & $>10 \mathrm{~km}$ & 84 & 7.7 \\
\hline
\end{tabular}

$S G A$ small for gestational age, $L G A$ large for gestational age, $L B W$ low birth weight

weight) (AHR:0.45, $95 \%$ CI: 0.24, 0.84). Neonates who were not initiated EBF had 7.5 times higher hazard of death than neonates who were initiated EBF (AHR: 7.5, 95 \% CI: 3.77, 15.60). Neonates born from mothers who did not have complications were $63 \%$ less likely to die

Table 4 Survival analysis of neonates during follow up time in the randomly selected hospitals of Tigray region, northern Ethiopia, April-July, $2014(n=1152)$

\begin{tabular}{llllcl}
\hline Interval & Total & Deaths & Lost & Survival probability $\%$ & $95 \% \mathrm{Cl}$ \\
\hline 0-1 day & 1152 & 15 & 1 & 98.70 & $97.8,99.2$ \\
1-7 day & 1136 & 35 & 3 & 95.65 & $94.3,96.7$ \\
$7-14$ & 1098 & 11 & 31 & 94.68 & $93.2,95.8$ \\
$14-12$ day & 1056 & 6 & 12 & 94.14 & $92.6,95.4$ \\
21-28 day & 1038 & 0 & 9 & 94.14 & $92.6,95.4$ \\
28 day & 1029 & 1 & 1028 & 93.96 & $92.4,95.2$ \\
\hline
\end{tabular}

$\mathrm{Cl}$ confidence interval than neonates born from mother's who had complications (AHR: 0.37, 95 \% CI: 0.22, 0.63). Neonates born from mothers residing in $\geq 10 \mathrm{~km}$ far from their nearest health facility had 2.5 times higher to die than neonates born from mothers residing within $\leq 5 \mathrm{~km}$ distance (AHR: 2.5, 95 \% CI: 1.29,4.91). Neonates who had no complication after birth had $99.86 \%$ lesser hazard of death than who had the complication (AHR: 0.14, $95 \%$ CI: 0.07, 0.29) (Table 6).

No confounding, effect modification and multicollinearity were observed in this study. No covariates violated the proportional-hazard assumption test. For the residual test, it was possible to conclude that the final model fits the data very well (Fig. 3).

\section{Discussion}

In this study, high NMR (62.5 per 1000 live births) was observed, which is striking because the deaths happened in hospitals where highly skilled birth attendants and formal health care system are present. This rate is higher than several studies conducted in Ethiopia and Africa [9, 11, 14, 31-34] and the national NM, EDHS 2011 report [4]. The discrepancy could be explained in terms of study design difference and the place where information was gathered, in which most of the mothers in our study and other hospital based studies [35] probably came very late with serious obstetric complications and may overestimate the community NM. However this could also be due to actual differences in rate of NM. Regardless, our data provided evidence as NM remains high in the study setting and the reasons remain uncertain. It is also much higher than the regional Health Management Information System report, which had reported that 20 neonatal deaths within five months period [21]. This can clearly show underreporting of neonatal mortalities for retrospective surveys and misclassification of stillbirths with ENM [3, 9]. This phenomenon is also similar to studies conducted in urban Pakistan and Africa, which showed a good access to health service and attendance by a skilled health professional were found to have high NM [36, 37], respectively. Hence, in our study settings, services being rendered to mothers and neonates seemed substandard, which is unacceptable in areas where services are attended by skilled birth attendants.

The incidence of ENM was higher than the LNM and the overall incidence is almost two times higher than the study findings of Butajira, Ethiopia [12]. This difference might be attributable to actual high incidence of NM in our study setting. It can also be because of the study area in which the Butajira study was conducted in a rural community, which was followed up for a longer 


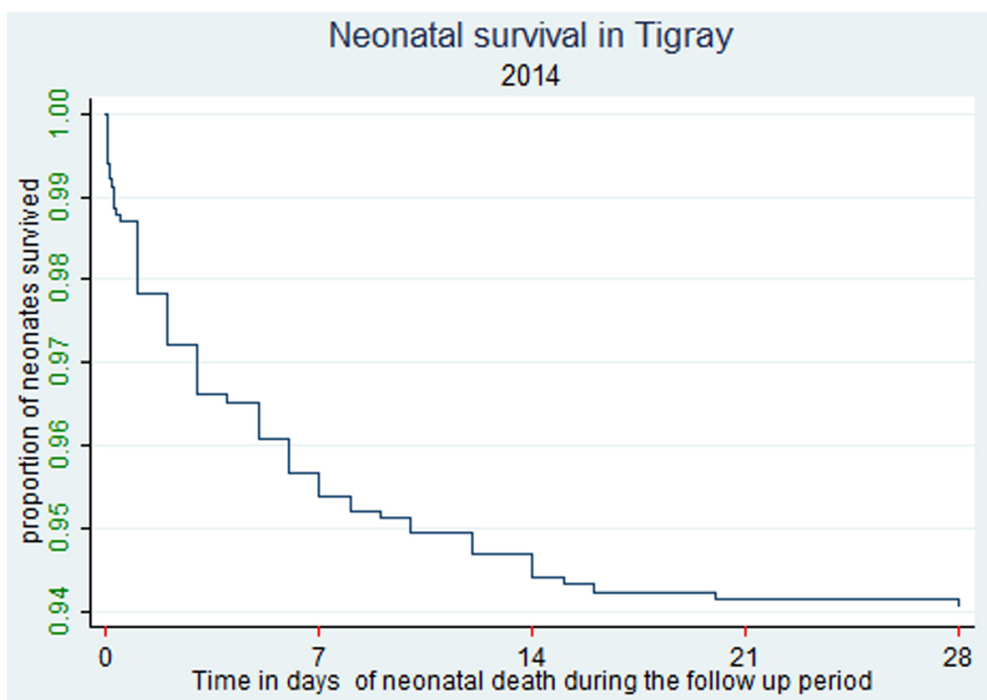

Fig. 2 Summary of Kaplan Meir survival estimate on the survival time of neonates born in Tigray region, northern Ethiopia, April-July, 2014 ( $n=1152$ ). The graph shows the proportion of neonates who survived during the follow up time (birth, 7, 14, 21 and 28 days). Accordingly, as can be seen from the graph; during the first seven days the graph went down gradually which shows a higher proportion of neonates were dying and there was a lower probability of survival. While, over the next 7 days ( 7 and 14), the proportion of neonates survived has slightly increased and the graph fell down slowly up to the third follow up time (21 day). In the last follow up period the graph became straight which indicates the proportion of neonates survived remained stable indicating virtually no deaths

Table 5 Log rank test result of variables for neonates born in randomly selected hospitals of Tigray region, northern Ethiopia, April -July, $2014(n=1152)$

\begin{tabular}{|c|c|c|c|c|c|}
\hline Variable & Log rank (X2) & $P$-value & Variable & Log rank (X2) & $P$-value \\
\hline Hospital & 6.05 & 0.418 & Tetanus injection & 2.17 & 0.1407 \\
\hline Age at current birth & 3.53 & 0.3163 & Rh immunization & 0.28 & 0.5983 \\
\hline Religion & 0.28 & 0.5943 & Mortality older sibling & 17.26 & 0.000 \\
\hline Residence & 13.09 & 0.0003 & Sex & 0.53 & 0.4661 \\
\hline Educational status & 7.1 & 0.0687 & Exclusive breast feed & 275.62 & 0.000 \\
\hline Occupation & 5.8 & 0.2149 & Time of breast feed & 2.7 & 0.1004 \\
\hline Income & 2.87 & 0.2387 & Place of death & 41.2 & 0.000 \\
\hline Marital status & 0.76 & 0.383 & Antenatal utilization & 3.06 & 0.0802 \\
\hline Number of children & 12.51 & 0.0019 & Distance & 32.11 & 0.000 \\
\hline Birth type & 29.11 & 0.000 & Mode of delivery & 5.44 & 0.0658 \\
\hline Gravidity & 6.8 & 0.0787 & Place of birth & 67.75 & 0.000 \\
\hline Birth interval & 3.79 & 0.1502 & Delivery Assistant & 9.38 & 0.0246 \\
\hline Family planning & 3.49 & 0.0619 & Birth weight & 135.93 & 0.000 \\
\hline Parity & 6.38 & 0.0947 & Gestational Age & 98.68 & 0.000 \\
\hline History of abortion & 9.66 & 0.0019 & Length of the neonate & 33.67 & 0.000 \\
\hline History of still birth & 17.11 & 0.000 & 1-min Apgar score & 475.4 & 0.000 \\
\hline Diagnosed disease & 0.73 & 0.3922 & 5-min Apgar score & 890.8 & 0.000 \\
\hline Maternal complication & 42.29 & 0.000 & Birth defect & 30.38 & 0.000 \\
\hline Temperature control & 165.67 & 0.000 & Neonatal complication & 316.14 & 0.000 \\
\hline Weight for GA & 19.49 & 0.000 & Hypothermia & 176.58 & 0.000 \\
\hline
\end{tabular}


Table 6 Multivariate Cox-proportional hazard model of predictors of neonatal mortality, delivered in randomly selected hospitals of Tigray region, northern Ethiopia, April-July, 2014 ( $n=1152)$

Characteristics Unadjusted HR $95 \% \mathrm{Cl} \quad$ Adjusted HR $95 \% \mathrm{Cl}$

\begin{tabular}{lll}
\hline Residence & & \\
Urban & 0.42 & $0.26,0.68$ \\
Rural (ref) & 1.00 &
\end{tabular}

Number of children

Prime (ref) $\quad 1.00$

2-4 children $\quad 0.73$

$0.41,1.29$

Multiple $>=5 \quad 2.3$

$1.26,4.23$

Birth type

Single (ref) $\quad 1.00$

Multiple $\quad 4.97$

$2.32,6.97$

History of abortion

$\begin{array}{ll}\text { Yes } & 0.44 \\ \text { No (ref) } & 1.00\end{array}$

$0.26,0.75$

History of still birth

Yes $\quad 0.31$

$0.17,0.55$

No (ref) $\quad 1.00$

Delivery complication

Yes (ref) $\quad 1.00$

No $\quad 0.23$

Exclusive breast feed

$\begin{array}{ll}\text { Yes (ref) } & 1.00 \\ \text { No } & 21.63\end{array}$

Distance to health facility

$\leq 5 \mathrm{~km}$ (ref) $\quad 1.00$

$5-10 \mathrm{~km} \quad 3.14$

$\geq 10 \mathrm{~km} \quad 4.64$

Mode of delivery

Spontaneous $\quad 1.00$

Vaginal (ref)

Cesarean $\quad 1.17$

section

Instrumental 2.38

1-min apgar score

Severe 1.00

asphyxia $(\leq 3)$

(ref)

Moderate

asphyxia (3-6)

Normal $(\geq 7) \quad 0.01$

5-min apgar score

Severe $\quad 1.00$

asphyxia $(\leq 3)$

(ref)
Table 6 Multivariate Cox-proportional hazard model of predictors of neonatal mortality, delivered in randomly selected hospitals of Tigray region, northern Ethiopia, April-July, 2014 ( $n=1152)$ (Continued)

\begin{tabular}{|c|c|c|c|c|}
\hline $\begin{array}{l}\text { Moderate } \\
\text { asphyxia (3-6) }\end{array}$ & 0.2 & \multicolumn{2}{|l|}{$0.088,0.45$} & \\
\hline Normal $(\geq 7)$ & 0.0055 & \multicolumn{2}{|l|}{$0.0023,0.012$} & \\
\hline \multicolumn{5}{|l|}{ Birth weight } \\
\hline$<2500 \mathrm{gm}$ & 11.49 & $4.49,29.39$ & 1.00 & \\
\hline $\begin{array}{l}2500-3500 \mathrm{gm} \\
\text { (ref) }\end{array}$ & 1.00 & & 0.45 & $\begin{array}{l}0.24 \\
0.84\end{array}$ \\
\hline$>3500 \mathrm{gm}$ & 1.19 & $0.46,3.08$ & 0.73 & $0.26,2.07$ \\
\hline \multicolumn{5}{|c|}{ Neonatal complication } \\
\hline Yes (ref) & 1.00 & & 1.00 & \\
\hline No & 0.04 & $0.024,0.068$ & 0.14 & $0.07,0.29$ \\
\hline \multicolumn{5}{|c|}{ Weight for GA adequacy } \\
\hline Adequate (ref) & 1.00 & & & \\
\hline SGA & 3.16 & $1.81,5.50$ & & \\
\hline LGA & 1.02 & $0.49,2.11$ & & \\
\hline \multicolumn{5}{|l|}{ Hypothermia } \\
\hline Yes (ref) & 1.00 & & & \\
\hline No & 0.075 & $0.046,0.12$ & & \\
\hline
\end{tabular}

HR hazard ratio, GA gestational age, SGA small for gestational age, LGA large for gestational age

period of time. However, the data for this study was collected from hospitals where mothers may have been diagnosed with complications. Despite the fact that we considered these possibilities, there is an intolerable high incidence of NM in our study setting.

Our study has revealed that most neonatal deaths occurred in the first $24 \mathrm{~h}$ and in the first week of life, which is consistent with different studies conducted before $[11,12,27,37,38]$. Other studies reported that most neonates died in their first week of life because of complication occurring during pregnancy and birth [13]. Poor quality of antenatal care, delay in identification and poor management of complications during pregnancy and birth by health workers might be the possible reasons.

The current study finding revealed that neonates with a low birth weight experienced higher mortality. This finding is similar to a study conducted in different parts of developing countries [3, 14, 17, 34, 38, 39]. Low birth weight contributes primarily from the mother's poor health and nutrition [40]. Improving obstetric care is crucial, which can reduce the incidence of low birth weight [41]. In this study, all triplets and most of twin births died, as low birth weight could be the result of preterm delivery or small size for gestational age. This could have happened because of poor 


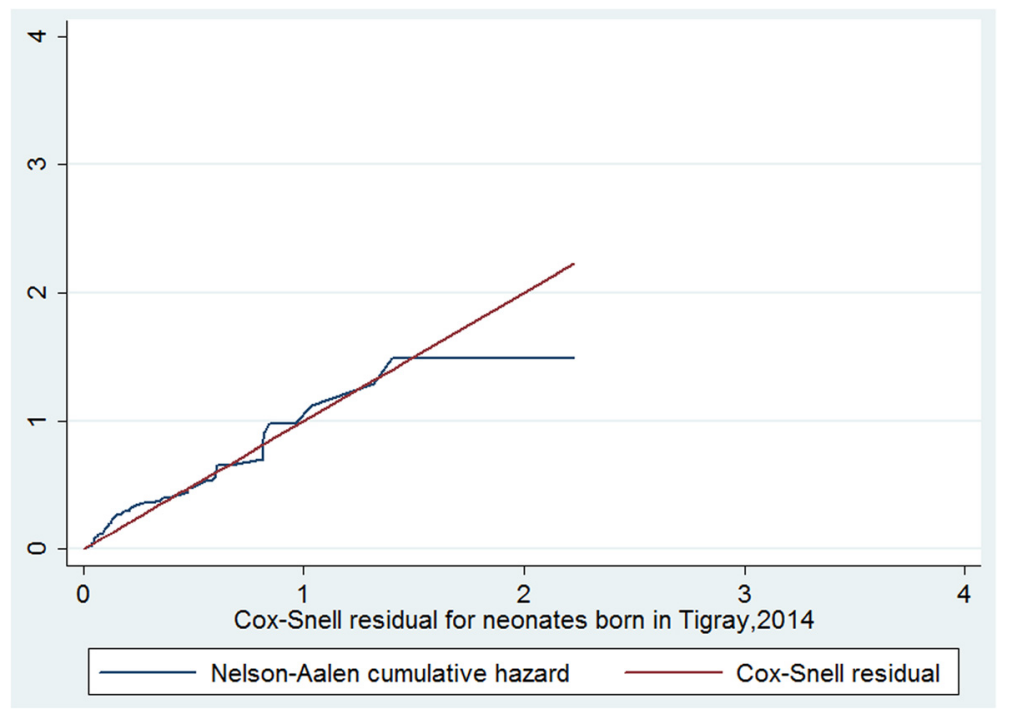

Fig. 3 Cox-Snell residual Nelson -Alen cumulative hazard graph on neonates born in Tigray region, Northern Ethiopia, April -July 2014. This figure shows if the Cox regression model fits the data, these residuals should have a standard censored exponential distribution with hazard ratio. The hazard function follows the $45^{\circ}$ line very closely

feeding practices of mothers, as well as subsequent malnutrition, inadequate warmth and lack of breastfeeding.

Our findings showed that neonates born from mothers who have complications during birth had a higher chance of death. This is similar to previous studies reported on maternal complications related to high risks of $\mathrm{NM}[3,16,27,34,42]$. However, recent studies from Africa [37] and Indonesia [43] showed that having delivery complications during birth have a protective effect on NM. Hence, these studies indicated that managing complications are possible, which may be related to the focus of skilled health professionals on mothers that have complications. This study considered the common maternal complications as the reasons for NM. This may be due to the quality and availability of services, including emergency obstetric services [7]. Weak integrated efforts in recognition of mothers with complications and delayed referrals by health workers could also be other reasons. This is supported by some studies' findings, which indicated that high NM often occurs because of delivery and pregnancy-related complications and denotes the quality of healthcare in an area [10].

In accordance with our findings, in general, studies show that male-presentation, prolonged labor, hemorrhage, infection, PROM and obstructed labor were associated with NM [3, 14, 27, 36, 39]. Accordingly, saving the mother and managing these complications could improve survival of neonates in our study setting.

Distance to the nearest health facility was also among the independent predictors of NM. Similarly, several studies also reported that neonates who live in remote and hard to reach areas from health facilities are at increased rate of death than those who live in nearby to the health facilities [12, 17, 28, 37, 39]. This can be explained in terms of lack of access to health service during pregnancy, which resulted in lower attendance rate at antenatal and delivery because of the distance [17]. It can be associated with missing opportunities to prevent and treat intrapartum complications and these circumstances may cause intra-partum complications and subsequent ENM.

The current study findings revealed that initiating EBF has a protective effect on hazards of NM. This is also reported by some studies, as EBF is essential to reduce newborn deaths [44]. Other studies reported that risk of NM delayed initiation of breastfeeding, where the risks were four times higher in children who were given other fluids in addition to breastmilk [45]. A study in subSaharan African countries demonstrated that NM could be reduced by $16 \%$ if mothers started breastfeeding from Day 1 and $22 \%$ if they started within the first hour [46]. Similarly, in our study, all neonates who did not initiate EBF had not initiated breastfeeding within the first one hour. Early initiation of breastfeeding is necessary to save newborn lives [24]. However, in our study, initiation of EBF seemed to be inadequately practiced and promoted. But it may be necessary to be cautious in interpreting this finding as sometimes neonates that are the most sick might be the least likely to be able to breastfeed compared to healthier neonates.

Neonatal complications are also one of the independent predictors for NM. In this study, the main causes of 
neonatal complications were: meconium aspiration, prematurity, low birth weight and prolonged labor, which lead to Apgar score less than 7 and birth asphyxia. The causes of complications result in neonatal asphyxia, hypothermia, sepsis and other complications, although there are no significant differences among them. Similarly, reports indicate that complications of prematurity are currently among the leading causes of NM [1, 2, 14]. A study conducted in South Africa revealed that neonatal complications were the causes for NM and morbidity like asphyxia and hypothermia [47]. This might be because of delay in identification of newborn complications, poor management and lack of postnatal care in our study settings.

The strength of this study is that it had included all predictors of NM and data collection was also complete and reliable. The study area covers the entire region of Tigray; it is generalizable to all hospitals of the region and Ethiopia. Limitations of this study are that the effect of seasonal variation on NM was not considered and the study was conducted only in public health institutions. Moreover, home deliveries and neonates who arrived at study hospitals after $6 \mathrm{~h}$ of birth were not considered as part of the study, as we failed to track the deaths that occurred at home and this may underestimate the NM rate because home deliveries are at risk of complications and deaths. We encountered $5.2 \%$ lost to follow up and withdrawals because mothers were unable to answer phone calls, meet with health extension workers and/or are not available during physical visits. Most of the mothers were moved from the original place of residence and their phone was not working during the follow up time. These mothers may encounter neonatal deaths that could underestimate our neonatal mortality rate.

\section{Conclusion}

In this study, unacceptably high burden and incidences of NM (lower survival) was observed, which is unexpected as the births were attended by highly skilled health workers. Moreover, proximate factors (maternal, neonatal and health service related factors) were the important predictors.

Therefore, a comprehensive effort should be undertaken to improve health service provided in the region, especially on the competency of health workers and quality of health services, including availability of necessary equipment and setup to manage neonatal and maternal complications. In addition, maternal health before delivery, including quality of antenatal care utilization, low birth weight, initiating exclusive breast feeding, continuum care of the neonate after discharge and access should be considered to improve survival time of neonates.

\section{Abbreviations}

AIDS, acquired immuno deficiency syndrome; BMI, body mass index; CPD, cephalo pelvic disproportion; EBF, exclusive breast feeding; ENM, early neonatal mortality; ETB, Ethiopian birr; HIV, human immunodeficiency virus; LNM, late neonatal mortality; NM, neonatal mortality; NMR, neonatal mortality rate; PROM, premature rupture of membrane; U5M, under-fivemortality; WHO, World Health Organization

\section{Acknowledgment \\ We thank to Tigray region health bureau, data collectors, Fiseha Ashebr, Haregweini Alemu, Surafel Berhe and mothers participated in this study for their invaluable contribution to the realization of this study. We are also indebted to Mekelle University, College of Health Sciences, Freweini G/kirstos and Degsihiwot G/hiwot for their unconditional support and encouragement.}

\section{Funding}

The authors have also declared that no financial support in the research, authorship and publication of this article was received.

\section{Availability of data and materials}

Data will be shared up on request and will be obtained by emailing to the corresponding author using "hayetgeb@gmail.com".

\section{Authors' contributions}

HG conceived the research, wrote the draft manuscript, carried out the analysis and interpretation. AD drafted the manuscript and revised it critically in the design and analysis of the research. WT was involved mainly in statistical analysis, design and revising in draft of the manuscript. TH was involved in revising the design and analysis of the research. All authors approved the final version of the manuscript.

\section{Competing interests}

The authors declared no potential competing interest with respect to the research, authorship and publication of this article.

\section{Consent for publication}

Not applicable.

\section{Ethical approval and consent}

Ethical clearance was obtained from Mekelle University, College of Health Sciences Ethical review board. Permission letters were also sought from Tigray Regional Health Bureau. Written Informed consent from the mother was obtained after clear explanation of the purpose of the study.

Confidentiality and anonymity was maintained.

Received: 21 June 2015 Accepted: 29 July 2016

Published online: 02 August 2016

\section{References}

1. UNICEF, World Health Organization, the World Bank, the United Nations Population Division: Levels \& Trends in Child Mortality: Estimates Developed by the UN Inter-agency Group for Child Mortality Estimation (UN IGME). UN IGME; 2014.

2. UNICEF, World Health Organization, the World Bank, the United Nations Population Division: Levels \& Trends in Child Mortality: Estimates Developed by the UN Inter-agency Group for Child Mortality Estimation (IGME). UN IGME; 2013.

3. Lawn JE, Cousens S, Zupan J. Lancet neonatal survival steering team. 4 million neonatal deaths: when? where? why? Lancet. 2005;365(9462):891-900.

4. Central Statistical Agency [Ethiopia] and ICF International. Ethiopia demographic and health survey 2011. Addis Ababa and Calverton: Central Statistical Agency and ICF International; 2012.

5. News from the last 10 kilometers. Ethiopia achieves millennium development goal on reducing child mortality!.Ethiopia: An L10K publication 2013; 2(1). Available from: http://www.10k.jsi.com. Accessed Aug 2014

6. UNICEF. In Ethiopia, a far reaching health worker programme has helped reduce child mortality across the country. 2013. Available from: http://www. unicef.org/infobycountry/ethiopia_70372.html.. Accessed Apr 2014. 
7. Kayongo M, Rubardt M, Butera J, Abdullah M, Mboninyibuka D, Madili M Making EmOC a reality-CARE's experiences in areas of high maternal mortality in Africa. Int J Gynecol Obstet. 2006;92:308-19.

8. Mekbib T, Kassaye E, Getachew A, Tadesse T, Debebe A. Averting maternal death and disability, the FIGO save the mothers initiative: the EthiopiaSweden collaboration. Int J Gynecol Obstet. 2003;81(1):93-102.

9. Oestergaard MZ, Inoue M, Yoshida S, et al. Neonatal mortality levels for 193 countries in 2009 with trends since 1990: a systematic analysis of progress, projections, and priorities. Plos Med. 2011;8(8):e1001080.

10. Lawn JE, Blencowe H, Pattinson R, et al. Stillbirths: where? when? why? how to make the data count? The Lancet. 2011;377:1448-63.

11. Gill CJ, Phiri-Mazala G, Guerina NG, et al. Effect of training traditional birth attendants on neonatal mortality (Lufwanyama Neonatal Survival Project): randomized controlled study. BMJ. 2011;342:d346.

12. Muluken G, Mitike M, Wubegzier M. Trends and risk factors for neonatal mortality in Butajira District, South Central Ethiopia, (1987-2008): a prospective cohort study. BMC Pregnancy Childbirth. 2014;14:64-70.

13. Jahan S. Poverty and infant mortality in the Eastern Mediterranean region: a Meta analysis. J Epidemiol Community Health. 2008;62(8):745-51.

14. Rahman S, Ansari EL. Neonatal mortality: incidence, correlates and improvement strategies. In: Oliver CE, Karen OP, editors. INTECH. 2012. p. 37-72.

15. Rahman S, Salameh K, Bener A, Ansarin WE. Socioeconomic associations of improved maternal, neonatal, and perinatal survival in Qatar. Int J Equity Health. 2010;2:311-8.

16. Emmanuel T, Notion G, Gerald S, Addmore C, Mufuta T, Simukai Z. Determinants of perinatal mortality in Marondera district, Mashonaland East Province of Zimbabwe, 2009 a case control study. Pan Afr Med J. 2011;8:7.

17. World Data Bank: World Development Indicators. The World Bank Group. 2013. Available from: http://www.worldbank.org/en/country/ethiopia. Accessed March 2014

18. Getachew B, Yifru B. Perinatal mortality and associated risk factors: a case control study. Ethiopian J Health Sci. 2012;22(3):153-61.

19. Darmstadt GL, Bhutta ZA, Cousens S, et al. Evidence-based, cost-effective interventions: how many newborn babies can we save? Lancet. 2005:365:977-88.

20. Zupan J. Perinatal mortality in developing countries. N Engl J Med. 2005:352:2047-8.

21. Tigray Region Health bureaue. Report on the health status of Tigray region. The government of the national state of Tigray; Mekelle. August 2014. Available from: http://www.trhb.gov.et. Acessed Nov 2014.

22. Yared M, Biruk T, Daniel ST, Tedbabe D, Abeba B. Neonatal mortality in Ethiopia: trends and determinants. BMC Public Health. 2013;13:483.

23. World Health Organization. Standard neonatal verbal autopsy questionnaire revised version. Geneva: WHO Publications; 2003.

24. Federal Ministry of Health, Ethiopia. Integrated management of newborn and child hood illness for health workers. 2011.

25. World Health Organization. International statistical classification of diseases and related health problem, 10th revision (ICD-100) Geneva: WHO; 2007.

26. Mosley $\mathrm{WH}$, Chen LC. An analytical framework for the study of child survival in developing countries. Popul Dev Rev. 1984;10:25-45.

27. World Health Organization. International statistics classification of diseases and related health problems.10th revision, vol. 2. Geneva: WHO; 1993.

28. World Health Organization. Physical status: the use and interpretation of anthropometry: report of a WHO expert committee. Lyon: World Health Organization; 1995.

29. Alexander GR, Himes JH, Kaufman RB, Mor J, Kogan M. A United States national reference for fetal growth. Obstet Gynecol. 1996;87:163-8.

30. World Health Organization. Thermal protection of the newborn: a practical guide. Geneva: World Health Organization; 1997.

31. Debelew GT, Afework MF, Yalew AW. Determinants and Causes of Neonatal Mortality in Jimma Zone, Southwest Ethiopia: A Multilevel Analysis of Prospective Follow up Study. PLoS ONE. 2014;9(9):e107184.

32. Yaya Y, Eide KT, Norheim OF, Lindtjorn B. Maternal and Neonatal Mortality in Southwest Ethiopia: Estimates and SocioEconomic Inequality. PLoS ONE. 2014;9(4):e96294.

33. Diallo AH, Meda N, Oue'draogo WT, Cousens S, Tylleskar T, For the PROMISE-EBF study group. A prospective study on neonatal mortality and its predictors in a rural area in Burkina Faso: can MDG-4 be met by 2015? J Perinatol. 2011;31:656-63.
34. Adetola AO, Tongo OO, Orimadegun AE, Osinusi K. Neonatal mortality in an urban population in Ibadan, Nigeria. Neonatal mortality in Ibadan, Nigeria. Pediatr Neonatol. 2011;52:243-50.

35. Berhan $Y$, Abdela A. Emergency obstetric performance with emphasis on operative delivery outcome: does it reflect the quality of care? Ethiop J Health Dev. 2004;18(2):96-106.

36. Jehan I, Harris $H$, Salat $\mathrm{S}$, et al. Neonatal mortality, risk factors and causes: a prospective population-based cohort study in urban Pakistan. Bull World Health Organ. 2009:87:130-8.

37. Singh K, Brodish P, Suchindran C. A regional multilevel analysis: can skilled birth attendants uniformly decrease neonatal mortality? Matern Child Health J. 2014;18(1):242-9.

38. Baqui AH, Ahmed S, Arifeen SE, et al. Effect of timing of first postnatal care home visit on neonatal mortality in Bangladesh: an observational cohort study. BMJ. 2009:339:2826.

39. Nankabirwa V, Tumwine JK, Tylleskär T, et al. Perinatal mortality in Eastern Uganda: a community based prospective cohort study. PLoS One. 2011;6(5):e19674.

40. Skokić F, Bačaj D, Selimović A, Hasanović E, Muratović S, Halilbašić A. Association of Low Birth Weight Infants and Maternal Socio demographic Status in Tuzla Canton during 1992-1995 War Periods in Bosnia and Herzegovina. Int J Pediatr. 2010:789183.

41. Onwuanaku CA, Okolo SN, Ige KO, Okpe SE, Toma BO. The effects of birth weight and gender on neonatal mortality in north central Nigeria. BMC Res Notes. 2011;4:562.

42. Kusiako T, Ronsmans C, Van der PL. Perinatal mortality attributable to complications of childbirth in Matlab, Bangladesh. Bull World Health Organ. 2000;78(5):621-7.

43. Titaley CR, Dibley MJ, Roberts CL. Type of delivery attendant, place of delivery and risk of early neonatal mortality: analyses of the 1994-2007 Indonesia Demographic and Health Surveys. Health Policy Plan. 2012; 27(5):405-16.

44. Begum K, Dewey KG. Impact of early initiation of exclusive breastfeeding on newborn deaths. Alive \& Thrive technical staff. 2010;1. Available from: http://www.alive and thrive.org. Accessed Nov 2014

45. Edmond KM, Zandoh C, Quigley MA, Amenga-Etego S, Owusu-Agyei S, Kirkwood RB. Delayed breastfeeding initiation increases risk of neonatal mortality. Pediatrics. 2006;117(3):380-6.

46. Edmond KM, Kirkword BR, Amenga-Etego S, Owusu-Ageyei S, HurtL S. Effect of early infant feeding practices on infection specific neonatal mortality: an investigation of the causal links with links with observational data from rural Ghana. Am J Cli Nutr. 2007:86(4):1126-31.

47. Kalimba EM, Ballot DE. Survival of extremely low-birth-weight infants: Department of Pediatrics and Child Health, University of the Witwatersrand and Charlotte Maxeke Johannesburg Academic Hospital, Johannesburg. S Afr J CH. 2013;7(1):13-16.

\section{Submit your next manuscript to BioMed Central and we will help you at every step:}

- We accept pre-submission inquiries

- Our selector tool helps you to find the most relevant journal

- We provide round the clock customer support

- Convenient online submission

- Thorough peer review

- Inclusion in PubMed and all major indexing services

- Maximum visibility for your research

Submit your manuscript at www.biomedcentral.com/submit 